\title{
Teori Titik Tetap Pemetaan C-kontraktif di Ruang Metrik Kompleks
}

\author{
Ahmad Ansar*1, Hikmah ${ }^{2}$ \\ ${ }^{1,2}$ Universitas Sulawesi Barat \\ e-mail:*11ahmad.ansar@unsulbar.ac.id, ${ }^{2}$ hikmah@unsulbar.ac.id
}

\begin{abstract}
Abstrak
Konsep titik tetap suatu pemetaan sangat terkait dengan ruang abstrak pemetaan tersebut berada. Ruang metrik kompleks merupakan perumuman dari ruang metrik. Dalam tulisan ini, dijelaskan mengenai eksistensi dan ketunggalan titik tetap pemetaan C-kontraktif di ruang metrik kompleks Selanjutnya, hasil yang diperoleh diperluas pada pemetaan C-kontraktif lemah dan ditunjukkan eksistensi dan ketunggalan titik tetapnya di ruang metrik kompleks.
\end{abstract}

Kata kunci-titik tetap, C-kontraktif, metrik kompleks

\section{PENDAHULUAN}

Teori titik tetap merupakan salah satu subjek yang banyak dikaji dalam bidang matematika analisis dikarenakan memiliki banyak aplikasi dalam bidang ekonomi, teknik, biologi dan sistem dinamik. Dalam bidang ekonomi teori titik tetap digunakan dalam menentukan titik ekulibrium dari fungsi permintaan dan penawaran. Selanjutnya, konsep titik tetap digunakan dalam menentukan solusi persamaan diferensial nonlinear .

Konsep titik tetap dibangun oleh dua komponen utama yaitu pemetaan kontraktif dan ruang dimana pemetaan kontraktif berada. Perkembangan teori ini dimulai dari pemetaan kontraksi Banach di ruang metrik yang dirumuskan oleh Stephan Banach. Selanjutnya, teori ini mengalami perkembangan dengan melakukan perluasan atau peumuman terhadap pemetaan kontraktif dan ruangnya. Salah satu perluasan konsep pemetaan kontraktif adalah pemetaan kontraktif lemah (weakly contractive mapping) dan pemetaan C-kontraktif. Selanjutnya, pemetaan C-kontraktif diperumum menjadi pemetaan C-kontraktif lemah. Dalam ruang metrik lengkap dapat ditunjukkan eksistensi dan ketunggalan titik tetap pemetaan C-kontraktif dan pemetaan Ckontraktif lemah.

Dilain pihak ruang metrik juga mengalami perumuman. Ruang metrik kompleks merupakan bentuk perumuman dari ruang metrik. Di dalam ruang metrik eksistensi titik tetap pemetaan C-kontraktif dan Ckontraktif lemah dapat ditunjukkan. Sementara eksistensi pemetaan C-kontraktif dan C-kontraktif lemah di ruang metrik kompleks belum dilakukan penelitian lebih mendalam. Oleh karena itu, penulis merasa perlu untuk mengakaji lebih dalam terkait eksistensi titik tetap pemetaan C-kontraktif dan C-kontraktif lemah di ruang metrik kompleks. Dalam penelitian ini dirumuskan teorema titik tetap pemetaan C-kontraktif dan teorema titik tetap pemetaan C-kontraktif lemah di ruang metrik kompleks.

\section{METODE PENELITIAN}

Penelitian ini merupakan penelitian studi literatur. Dalam penelitian dikumpulkan berbagai buku dan artikel-artikel dari berbagai jurnal yang membahas konsep ruang metrik kompleks dan pemetaan C-kontraktif. Selanjutnya, dirumuskan teorema titik tetap pemetaan C-kontraktif dan C-kontraktif lemah di ruang metrik kompleks. 
https://jurnal.unsulbar.ac.id/index.php/saintifik

Pada bagian ini akan dijelaskan teori pendukung dalam menenjukkan eksistensi titik tetap pemetaan C-kontraktif lemah di ruang metrik kompleks.

\subsection{Ruang Metrik Bernilai Kompleks}

Ruang metrik bernilai kompleks atau ruang metrik kompleks dirumuskan oleh Azam et al. Diberikan $\mathbb{C}$ himpunan semua bilangan kompleks dan $z_{1}, z_{2} \in \mathbb{C}$. Didefinisikan urutan parsial $\precsim$ pada $\mathbb{C}$ dengan

$$
z_{1} \precsim z_{2} \text { jika dan hanya jika } \operatorname{Re}\left(z_{1}\right) \leq \operatorname{Re}\left(z_{2}\right) \text { dan } \operatorname{Im}\left(z_{1}\right) \leq \operatorname{Im}\left(z_{2}\right)
$$

Dalam tulisan ini, notasi $\mathbb{C}^{+}$didefinisikan sebagai

$$
\mathbb{C}^{+}=\left\{z=x+i y \mid x \in \mathbb{R}^{+} \text {dan } y \in \mathbb{R}^{+}\right\}
$$

Menggunakan urutan parsial tersebut didefinisikan ruang metrik kompleks. Berikut diberikan definisi ruang metrik kompleks.

\section{Definisi 2.1}

Diberikan himpunan tak kosong $X$. Pemetaan $d_{c}: X \times X \rightarrow \mathbb{C}$ disebut metrik kompleks pada $X$ apabila untuk setiap $x, y, z \in \mathbb{C}$ memenuhi

i. $\quad 0 \precsim d_{c}(x, y)$

ii. $\quad d_{c}(x, y)=0$ jika dan hanya jika $x=y$

iii. $\quad d_{c}(x, y)=d_{c}(y, x)$

iv. $\quad d_{c}(x, y) \precsim d_{c}(x, z)+d_{c}(z, y)$

Pasangan $\left(X, d_{c}\right)$ disebut ruang metrik kompleks.

Berikut diberikan definisi barisan konvergen dan barisan Cauchy di ruang metrik kompleks serta teorema terkait sesuai yang dijelaskan oleh Azam et.al.

\section{Definisi 2.2}

Diberikan ruang metrik kompleks $\left(X, d_{c}\right)$, barisan $\left\{x_{n}\right\} \subseteq X$ dan $x \in X$. Barisan $\left\{x_{n}\right\}$ dikatakan konvergen ke $x$, apabila untuk setiap $c \in \mathbb{C}$ dengan $c \succ 0$ terdapat $N \in \mathbb{N}$ sehingga untuk setiap $n>N$ berlaku $d\left(x_{n}, x\right) \prec c$.

Barisan $\left\{x_{n}\right\}$ yang konvergen ke $x$ ditulis $\lim _{n \rightarrow \infty} x_{n}=x$ dan $x$ disebut titik limit dari $\left\{x_{n}\right\}$.

\section{Teorema 2.3}

Diberikan ruang metrik kompleks $\left(X, d_{c}\right)$ dan barisan $\left\{x_{n}\right\} \subseteq X$. Barisan $\left\{x_{n}\right\}$ konvergen ke $x$ jika dan hanya jika $\left|d_{c}\left(x_{n}, x\right)\right| \rightarrow 0$ untuk $n \rightarrow \infty$

\section{Definisi 2.4.}

Diberikan ruang metrik kompleks $\left(X, d_{c}\right)$ dan barisan $\left\{x_{n}\right\} \subseteq X$. Barisan $\left\{x_{n}\right\}$ dikatakan barisan Cauchy, apabila untuk setiap $c \in \mathbb{C}$ dengan $c \succ 0$ terdapat $N \in \mathbb{N}$ sehingga untuk setiap $n \geq N$ berlaku $d_{c}\left(x_{n}, x_{n+m}\right) \prec c$ untuk $m \in \mathbb{N}$.

Jika setiap barisan Cauchy konvergen di $\left(X, d_{c}\right)$, maka $\left(X, d_{c}\right)$ disebut ruang metrik kompleks lengkap.

\section{Teorema 2.5}


Diberikan ruang metrik kompleks $\left(X, d_{c}\right)$ dan barisan $\left\{x_{n}\right\} \subseteq X$. Barisan $\left\{x_{n}\right\}$ adalah barisan Cauchy jika dan hanya jika $\left|d_{c}\left(x_{n}, x_{m}\right)\right| \rightarrow 0$ untuk $n \rightarrow \infty$

\subsection{Pemetaan Kontraktif dan Titik Tetap}

Diberikan $(X, d)$ ruang metrik. Pemetaan $T: X \rightarrow X$ disebut pemetaan kontraktif apabila terdapat bilangan $0<k<1$ sehingga untuk setiap $x, y \in X$ berlaku

$$
d(T(x), T(y)) \leq k d(x, y)
$$

Untuk setiap $x \in X$ didefiniskan $T^{n+1}(x)=T\left(T^{n}(x)\right)$. Titik $x \in X$ disebut titik tetap fungsi $T: X \rightarrow X$ apabila $T(x)=x$.Menggunakan pemetaan kontraktif di ruang metrik lengkap, maka dapat ditunjukkan bahwa $T$ mempunyai titik tetap tunggal. Teorema tersebut dikenal sebagai Teorema Titik Banach seperti yang dijelaskan Banach dalam artikelnya.

Teorema 2.6

Jika $(X, d)$ merupakan ruang metrik lengkap dan $T: X \rightarrow X$ merupakan pemetaan kontraktif maka $T$ mempunyai titik tetap tunggal.

Pemetaan kontraktif dapat diperumum dengan menggunakan fungsi naik monoton yang kontinu dan dikenal dengan pemetaan kontraksi lemah. Hal ini sesuai dengan yang dijelaskan Rhoades sebagai berikut.

\section{Definisi 2.7}

Diberikan $(X, d)$ ruang metrik. Pemetaan $T: X \rightarrow X$ disebut pemetaan kontraktif lemah apabila terdapat fungsi $\varphi:[0, \infty) \rightarrow[0, \infty)$ kontinu, naik monoton dan memenuhi $\varphi(t)=0$ jika dan hanya jika $t=0$ sehingga untuk setiap $x, y \in X$ berlaku

$$
d(T(x), T(y)) \leq d(x, y)-\varphi(d(x, y))
$$

\section{Teorema 2.8}

Jika $(X, d)$ merupakan ruang metrik lengkap dan $T: X \rightarrow X$ merupakan pemetaan kontraktif maka $T$ mempunyai titik tetap tunggal.

\subsection{Pemataan C-kontraktif}

Chatterjea merumuskan konsep C-kontraktif dan menunjukkan eksistensi titik tetapnya di ruang metrik.

\section{Definisi 2.9}

Diberikan $(X, d)$ ruang metrik. Pemetaan $T: X \rightarrow X$ disebut pemetaan C-kontraktif apabila terdapat $0<k<\frac{1}{2}$ sehingga untuk setiap $x, y \in X$ berlaku

$$
d(T(x), T(y)) \leq k[d(x, T(y))+d(T(x), y)]
$$

\section{Teorema 2.10}

Jika $(X, d)$ merupakan ruang metrik lengkap dan $T: X \rightarrow X$ merupakan pemetaan C-kontraktif maka $T$ mempunyai titik tetap tunggal.

Selanjutnya, Choudhury menunjukkan eksistensi dan ketunggalan titik tetap pemetaan C-kontraktif di ruang metrik. 


\section{Definisi 2.11}

Diberikan $(X, d)$ ruang metrik. Pemetaan $T: X \rightarrow X$ disebut pemetaan C-kontraktif lemah apabila terdapat fungsi $\varphi:[0, \infty)^{2} \rightarrow[0, \infty)$ kontinu dan memenuhi $\varphi(x, y)=0$ jika dan hanya jika $x=0=y$ sehingga untuk setiap $x, y \in X$ berlaku

$$
d(T(x), T(y)) \leq \frac{1}{2}[d(x, T(y))+d(T(x), y)]-\varphi(d(x, T(y)), d(T(x), y))
$$

\section{Teorema 2.12}

Jika $(X, d)$ merupakan ruang metrik lengkap dan $T: X \rightarrow X$ merupakan pemetaan C-kontraktif lemah maka $T$ mempunyai titik tetap tunggal..

\section{TEORI TITIK TETAP DI RUANG METRIK KOMPLEKS}

Pada bagian ini ditunjukkan titik tetap pemetaan C-kontraktif di ruang metrik kompleks.

\section{Definisi 3.1}

Diberikan $\left(X, d_{c}\right)$ ruang metrik kompleks. Pemetaan $T: X \times X \rightarrow \mathbb{C}$ disebut pemetaan C-kontraktif di ruang metrik kompleks apabila terdapat $0<k<\frac{1}{2}$ sehingga untuk setiap $x, y \in X$ berlaku

$$
d_{c}(T(x), T(y)) \precsim k\left[d_{c}(x, T(y))+d_{c}(T(x), y)\right]
$$

Dengan menggunakan definisi di atas, maka Teorema 2.10 dapat diperluas di ruang metrik kompleks lengkap. Teorema 3.2

Diberikan $\left(X, d_{c}\right)$ ruang metrik kompleks lengkap. Jika $T: X \rightarrow X$ merupakan pemetaan C-kontraktif, maka $T$ mempunyai titik tetap yang tunggal.

\section{Bukti:}

Ambil sebarang $x_{0} \in X$. Untuk setiap $n \in \mathbb{N}$ didefinisikan barisan

$T^{n+1}\left(x_{0}\right)=T\left(x_{n}\right)=x_{n+1}$

Jika $x_{n}=x_{n+1}=T\left(x_{n}\right)$, maka $x_{n}$ merupakan titik tetap $T$.

Jika $x_{n} \neq x_{n+1}$, maka

$$
\begin{aligned}
d_{c}\left(x_{n}, x_{n+1}\right) & =d_{c}\left(T\left(x_{n-1}\right), T\left(x_{n}\right)\right) \\
& \precsim k\left[d_{c}\left(x_{n-1}, T\left(x_{n}\right)\right)+d_{c}\left(x_{n}, T\left(x_{n-1}\right)\right)\right] \\
& =k\left[d_{c}\left(x_{n-1}, x_{n+1}\right)+d_{c}\left(x_{n}, x_{n}\right)\right] \\
& =k d_{c}\left(x_{n-1}, x_{n+1}\right) \\
& \precsim k\left[d_{c}\left(x_{n-1}, x_{n}\right)+d_{c}\left(x_{n}, x_{n+1}\right)\right]
\end{aligned}
$$

Diperoleh 
https://jurnal.unsulbar.ac.id/index.php/saintifik

$$
\begin{aligned}
(1-k) d_{c}\left(x_{n}, x_{n+1}\right) & \precsim k \cdot d_{c}\left(x_{n-1}, x_{n}\right) \\
d_{c}\left(x_{n}, x_{n+1}\right) & \precsim \frac{k}{1-k} \cdot d_{c}\left(x_{n-1}, x_{n}\right) \\
& \precsim\left(\frac{k}{1-k}\right)^{2} d_{c}\left(x_{n-2}, x_{n-1}\right) \\
& \precsim\left(\frac{k}{1-k}\right)^{n} d_{c}\left(x_{0}, x_{1}\right)
\end{aligned}
$$

Oleh karena itu,

$$
\begin{aligned}
d_{c}\left(x_{n}, x_{n+m}\right) & \precsim d_{c}\left(x_{n}, x_{n+1}\right)+d_{c}\left(x_{n+1}, x_{n+m}\right) \\
& \precsim d_{c}\left(x_{n}, x_{n+1}\right)+d_{c}\left(x_{n+1}, x_{n+2}\right)+\ldots+d_{c}\left(x_{n+m-1}, x_{n+m}\right) \\
& \precsim\left(\frac{k}{1-k}\right)^{n} d_{c}\left(x_{0}, x_{1}\right)+\left(\frac{k}{1-k}\right)^{n+1} d_{c}\left(x_{0}, x_{1}\right)+\ldots+\left(\frac{k}{1-k}\right)^{n+m-1} d_{c}\left(x_{0}, x_{1}\right) \\
& =\left(\frac{k}{1-k}\right)^{n} d_{c}\left(x_{0}, x_{1}\right)\left[1+\left(\frac{k}{1-k}\right)+\ldots\left(\frac{k}{1-k}\right)^{m-1}\right] \\
& \precsim\left(\frac{k}{1-k}\right)^{n} d_{c}\left(x_{0}, x_{1}\right)\left[\frac{1-k}{1-2 k}\right]
\end{aligned}
$$

Karena $k \in\left(0, \frac{1}{2}\right)$, maka $\frac{k}{1-k} \in\left(0, \frac{1}{2}\right)$. Akibatnya untuk $n \rightarrow \infty$, diperoleh

$$
0 \leq \lim _{n \rightarrow \infty}\left|d_{c}\left(x_{n}, x_{n+m}\right)\right| \leq \lim _{n \rightarrow \infty}\left|\left(\frac{k}{1-k}\right)^{n} d_{c}\left(x_{0}, x_{1}\right)\right|=0
$$

Jadi barisan $\left\{x_{n}\right\}$ adalah barisan Cauchy di $X$, sehingga $\left\{x_{n}\right\}$ adalah barisan konvergen. Misalkan barisan $\left\{x_{n}\right\}$ konvergen ke $x \in X$. Perhatikan bahwa

$$
\begin{aligned}
d_{c}(x, T(x)) & \precsim d_{c}\left(x, x_{n+1}\right)+d_{c}\left(x_{n+1}, T(x)\right) \\
& =d_{c}\left(x, x_{n+1}\right)+k\left[d_{c}\left(x_{n}, T(x)\right)+d_{c}\left(x, T\left(x_{n}\right)\right)\right] \\
& =(1+k) d_{c}\left(x, x_{n+1}\right)+k d_{c}\left(x_{n}, T(x)\right) \\
& \precsim(1+k) d_{c}\left(x, x_{n+1}\right)
\end{aligned}
$$

Untuk $n \rightarrow \infty$, maka

$$
0 \leq \lim _{n \rightarrow \infty}\left|d_{c}(x, T(x))\right| \leq \lim _{n \rightarrow \infty}\left|(1+k) d_{c}\left(x, x_{n+1}\right)\right|=0
$$

Oleh karena itu, $\lim _{n \rightarrow \infty}\left|d_{c}(x, T(x))\right|=0$ atau $\left|d_{c}(x, T(x))\right|=0$ atau $T(x)=x$. Jadi $x \in X$ adalah titik tetap pemetaan $T$.

Andaikan $z \in X$ adalah titik tetap yang lain yaitu $T(z)=z$. Perhatikan bahwa

$$
\begin{aligned}
d_{c}(z, x) & =d_{c}(T(z), T(x)) \\
& \precsim k\left[d_{c}(z, T(x))+d_{c}(x, T(z))\right] \\
& =k\left[d_{c}(z, x)+d_{c}(x, z)\right] \\
& =k\left[2 d_{c}(z, x)\right]
\end{aligned}
$$

Karena $k \in\left(0, \frac{1}{2}\right)$, maka $\left|d_{c}(z, x)\right| \leq\left|2 k d_{c}(z, x)\right|$ hanya berlaku jika $d_{c}(z, x)=0$ atau $x=z$. Jadi $T$ mempunyai titik tetap tunggal. 
Teorema di atas dapat diperluas menggunakan pemetaan C-kontraktif lemah. Berikut diberikan definisi pemetaan C-kontraktif lemah di ruang metrik kompleks.

\section{Definisi 3.3}

Diberikan $\left(X, d_{c}\right)$ ruang metrik kompleks. Pemetaan $T: X \rightarrow X$ disebut pemetaan C-kontraktif lemah apabila untuk setiap $x, y, z \in X$ berlaku

$$
d_{c}(T(x), T(y)) \leq \frac{1}{2}\left[d_{c}(x, T(y))+d_{c}(T(x), y)\right]-\varphi\left(d_{c}(x, T(y)), d_{c}(T(x), y)\right)
$$

dengan $\varphi: \mathbb{C}^{+} \times \mathbb{C}^{+} \rightarrow \mathbb{C}^{+}$merupakan fungsi kontinu sehingga $\varphi\left(z_{1}, z_{2}\right)=0$ jika dan hanya jika $z_{1}=0=z_{2}$.

Menggunakan definisi di atas, maka Teorema 2.12 dapat diperluas di ruang metrik kompleks lengkap seperti yang dijelaskan dalam teorema berikut.

\section{Teorema 3.4}

Diberikan $\left(X, d_{c}\right)$ ruang metrik kompleks lengkap. Jika $T: X \rightarrow X$ merupakan pemetaan C-kontraktif lemah, maka $T$ mempunyai titik tetap yang tunggal.

\section{Bukti:}

Diambil sebarang $x_{0} \in X$. Untuk setiap $n \in \mathbb{N}$ didefinisikan $T\left(x_{n}\right)=x_{n+1}$.

Jika $x_{n}=x_{n+1}=T\left(x_{n}\right)$, maka $x_{n}$ adalah titik tetap dari pemetaan $T$.

Misalkan $x_{n} \neq x_{n+1}$. Perhatikan bahwa

$$
\begin{aligned}
d_{c}\left(x_{n}, x_{n+1}\right) & =d_{c}\left(T\left(x_{n-1}\right), T\left(x_{n}\right)\right) \\
& \precsim \frac{1}{2}\left[d_{c}\left(x_{n-1}, T\left(x_{n}\right)\right)+d_{c}\left(x_{n}, T\left(x_{n-1}\right)\right)\right]-\varphi\left(d_{c}\left(x_{n-1}, T\left(x_{n}\right)\right), d_{c}\left(x_{n}, T\left(x_{n-1}\right)\right)\right) \\
& =\frac{1}{2} d_{c}\left(x_{n-1}, x_{n+1}\right)-\varphi\left(d_{c}\left(x_{n-1}, x_{n+1}\right), 0\right) \\
& \precsim \frac{1}{2}\left[d_{c}\left(x_{n-1}, x_{n}\right)+d_{c}\left(x_{n}, x_{n+1}\right)\right]-\varphi\left(d_{c}\left(x_{n-1}, x_{n+1}\right), 0\right) \\
& \precsim \frac{1}{2}\left[d_{c}\left(x_{n-1}, x_{n}\right)+d_{c}\left(x_{n}, x_{n+1}\right)\right]
\end{aligned}
$$

Jadi untuk setiap $n \in \mathbb{N}$ berlaku

$$
d_{c}\left(x_{n}, x_{n+1}\right) \precsim d_{c}\left(x_{n-1}, x_{n}\right)
$$

Berdasarkan urutan parsial di $\mathbb{C}$ yang telah didefinisikan sebelumnya, maka barisan $\left\{d_{c}\left(x_{n}, x_{n+1}\right)\right\}$ dengan $\operatorname{Re}\left(d_{c}\left(x_{n}, x_{n+1}\right)\right)$ merupakan barisan bilangan real positif yang turun monoton dan $\operatorname{Im}\left(d_{c}\left(x_{n}, x_{n+1}\right)\right)$ merupakan barisan bilangan real positif yang turun monoton. Akibatnya, barisan $\left\{\operatorname{Re}\left(d_{c}\left(x_{n}, x_{n+1}\right)\right)\right\}$ dan barisan $\left\{\operatorname{Im}\left(d_{c}\left(x_{n}, x_{n+1}\right)\right)\right\}$ merupakan barisan yang konvergen. Misalkan barisan $\left\{d_{c}\left(x_{n}, x_{n+1}\right)\right\}$ konvergen ke $z=x+i y \in \mathbb{C}$ dengan $\operatorname{Re}\left(d_{c}\left(x_{n}, x_{n+1}\right)\right)$ konvergen ke $x \in \mathbb{R}$ dan $\operatorname{Im}\left(d_{c}\left(x_{n}, x_{n+1}\right)\right)$ konveregen ke $y \in \mathbb{R}$.

Akan ditunjukkan bahwa $z=0$. Perhatikan bahwa 


$$
\begin{aligned}
d_{c}\left(x_{n}, x_{n+1}\right) & =d_{c}\left(T\left(x_{n-1}\right), T\left(x_{n}\right)\right) \\
& \precsim \frac{1}{2}\left[d_{c}\left(x_{n-1}, T\left(x_{n}\right)\right)+d_{c}\left(x_{n}, T\left(x_{n-1}\right)\right)\right]-\varphi\left(d_{c}\left(x_{n-1}, T\left(x_{n}\right)\right), d_{c}\left(x_{n}, T\left(x_{n-1}\right)\right)\right) \\
& \precsim \frac{1}{2} d_{c}\left(x_{n-1}, x_{n+1}\right) \\
& \precsim \frac{1}{2}\left[d_{c}\left(x_{n-1}, x_{n}\right)+d_{c}\left(x_{n}, x_{n+1}\right)\right]
\end{aligned}
$$

Untuk $n \rightarrow \infty$, maka

$$
\begin{aligned}
z=\lim _{n \rightarrow \infty} d_{c}\left(x_{n}, x_{n+1}\right) & \precsim \lim _{n \rightarrow \infty} \frac{1}{2} d_{c}\left(x_{n-1}, x_{n+1}\right) \\
& \precsim \frac{1}{2} \lim _{n \rightarrow \infty}\left[d_{c}\left(x_{n-1}, x_{n}\right)+d_{c}\left(x_{n}, x_{n+1}\right)\right] \\
& =\frac{1}{2}(z+z) \\
& =z
\end{aligned}
$$

Jadi $\lim _{n \rightarrow \infty} \frac{1}{2} d_{c}\left(x_{n-1}, x_{n+1}\right)=z$ atau $\lim _{n \rightarrow \infty} d_{c}\left(x_{n-1}, x_{n+1}\right)=2 z$

Karena $\quad d_{c}\left(x_{n}, x_{n+1}\right) \precsim \frac{1}{2}\left[d_{c}\left(x_{n-1}, x_{n}\right)+d_{c}\left(x_{n}, x_{n+1}\right)\right]-\varphi\left(d_{c}\left(x_{n-1}, x_{n+1}\right), 0\right) \quad$ dan $\quad\left\{d_{c}\left(x_{n}, x_{n+1}\right)\right\}$ konvergen ke $z=x+i y \in \mathbb{C}$, maka untuk $n \rightarrow \infty$ diperoleh $z \precsim z-\varphi(2 z, 0)$ atau $\varphi(2 z, 0) \precsim 0$. Karena $\varphi: \mathbb{C}^{+} \times \mathbb{C}^{+} \rightarrow \mathbb{C}^{+}$kontinu dan memenuhi $\varphi(x, y)=0$ jika dan hanya jika $x=0=y$, maka $z=0$. Jadi barisan $\left\{d_{c}\left(x_{n}, x_{n+1}\right)\right\}$ konvergen ke 0 .

Selanjutnya, ditunjukkan bahwa barisan $\left\{x_{n}\right\} \subseteq X$ adalah barisan Cauchy.

Andaikan $\left\{x_{n}\right\} \subseteq X$ bukan barisan Cauchy, berarti terdapat $c_{0} \in \mathbb{C}$ dengan $c_{0} \succ 0$ sehingga terdapat subbarisan $\left\{x_{n_{k}}\right\}$ dan $\left\{x_{m_{k}}\right\} \subseteq\left\{x_{n}\right\}$ dengan $n_{k}>m_{k}>k$ sehingga untuk setiap $k \in \mathbb{N}$ berlaku

$$
d_{c}\left(x_{n_{k}}, x_{m_{k}}\right) \succsim c_{0}
$$

Untuk bilangan asli $n_{k}$ terkecil yang memenuhi $n_{k}>m_{k}$ dan memenuhi (10), maka berlaku

$$
d_{c}\left(x_{n_{k}-1}, x_{m_{k}}\right) \prec c_{0}
$$

Perhatikan bahwa

$$
\begin{aligned}
c_{0} & \precsim d_{c}\left(x_{n_{k}}, x_{m_{k}}\right) \\
& =d_{c}\left(T\left(x_{n_{k}-1}\right), T\left(x_{m_{k}-1}\right)\right) \\
& \precsim \frac{1}{2}\left[d_{c}\left(x_{n_{k}-1}, T\left(x_{m_{k}-1}\right)\right)+d_{c}\left(x_{m_{k}-1}, T\left(x_{n_{k}-1}\right)\right)\right]-\varphi\left(d_{c}\left(x_{n_{k}-1}, T\left(x_{m_{k}-1}\right)\right), d_{c}\left(x_{m_{k}-1}, T\left(x_{n_{k}-1}\right)\right)\right) \\
& =\frac{1}{2}\left[d_{c}\left(x_{n_{k}-1}, x_{m_{k}}\right)+d_{c}\left(x_{m_{k}-1}, x_{n_{k}}\right)\right]-\varphi\left(d_{c}\left(x_{n_{k}-1}, x_{m_{k}}\right), d_{c}\left(x_{m_{k}-1}, x_{n_{k}}\right)\right)
\end{aligned}
$$

Selanjutnya, 
https://jurnal.unsulbar.ac.id/index.php/saintifik

$$
\begin{aligned}
c_{0} & \precsim d_{c}\left(x_{m_{k}}, x_{n_{k}}\right) \\
& \precsim d_{c}\left(x_{m_{k}}, x_{n_{k}-1}\right)+d_{c}\left(x_{n_{k}-1}, x_{n_{k}}\right) \\
& \precsim c_{0}+d_{c}\left(x_{n_{k}-1}, x_{n_{k}}\right)
\end{aligned}
$$

Untuk $k \rightarrow \infty$,

$$
\begin{aligned}
c_{0} \precsim \lim _{k \rightarrow \infty} d_{c}\left(x_{m_{k}}, x_{n_{k}}\right) & \precsim c_{0}+\lim _{k \rightarrow \infty} d_{c}\left(x_{n_{k}-1}, x_{n_{k}}\right) \\
& =c_{0}+0 \\
& =c_{0}
\end{aligned}
$$

Jadi $\lim _{k \rightarrow \infty} d_{c}\left(x_{m_{k}}, x_{n_{k}}\right)=c_{0}$

Perhatikan bahwa

$$
\begin{aligned}
d_{c}\left(x_{m_{k}}, x_{n_{k}-1}\right) & \precsim d_{c}\left(x_{m_{k}}, x_{m_{k}-1}\right)+d_{c}\left(x_{m_{k}-1}, x_{n_{k}-1}\right) \\
& \precsim d_{c}\left(x_{m_{k}}, x_{m_{k}-1}\right)+d_{c}\left(x_{m_{k}-1}, x_{n_{k}}\right)+d_{c}\left(x_{n_{k}}, x_{n_{k}-1}\right)
\end{aligned}
$$

dan

$$
d_{c}\left(x_{m_{k}-1}, x_{n_{k}}\right) \precsim d_{c}\left(x_{m_{k}-1}, x_{m_{k}}\right)+d_{c}\left(x_{m_{k}}, x_{n_{k}}\right)
$$

Diperoleh

$$
\begin{aligned}
c_{0} & \precsim 0+d_{c}\left(x_{m_{k}-1}, x_{n_{k}}\right)+0 \\
& =d_{c}\left(x_{m_{k}-1}, x_{n_{k}}\right)
\end{aligned}
$$

dan

$$
d_{c}\left(x_{m_{k}-1}, x_{n_{k}}\right) \precsim 0+c_{0}
$$

Jadi $\lim _{k \rightarrow \infty} d_{c}\left(x_{m_{k}-1}, x_{n_{k}}\right)=c_{0}$

Untuk $n_{k}>m_{k}$, maka

$$
\begin{aligned}
c_{0} & \precsim d_{c}\left(x_{m_{k}}, x_{n_{k}}\right) \\
& =\frac{1}{2}\left[d_{c}\left(x_{m_{k}-1}, x_{n_{k}}\right)+d_{c}\left(x_{n_{k}-1}, x_{m_{k}}\right)\right]-\varphi\left(d_{c}\left(x_{m_{k}-1}, x_{n_{k}}\right), d_{c}\left(x_{n_{k}-1}, x_{m_{k}}\right)\right)
\end{aligned}
$$

Untuk $k \rightarrow \infty$, maka diperoleh

$$
c_{0} \precsim \frac{1}{2}\left(c_{0}+c_{0}\right)-\varphi\left(c_{0}, c_{0}\right)
$$

Akibatnya, $\varphi\left(c_{0}, c_{0}\right)=0$ atau $c_{0}=0$. Jadi barisan $\left\{x_{n}\right\} \subseteq X$ adalah barisan Cauchy. Karena $X$ adalah ruang metrik kompleks lengkap, maka terdapat $x \in X$ sehingga barisan $\left\{x_{n}\right\}$ konvergen ke $x$.

Selanjutnya, ditunjukkan bahwa pemetaan $T$ mempunyai titik tetap tunggal. Perhatikan bahwa

$$
\begin{aligned}
d_{c}(x, T(x)) & \precsim d_{c}\left(x, x_{n+1}\right)+d_{c}\left(x_{n+1}, T(x)\right) \\
& =d_{c}\left(x, x_{n+1}\right)+d_{c}\left(T\left(x_{n}\right), T(x)\right) \\
& \precsim d_{c}\left(x, x_{n+1}\right)+\frac{1}{2}\left[d_{c}\left(x_{n}, T(x)\right)+d_{c}\left(x, T\left(x_{n}\right)\right)\right]-\varphi\left(d_{c}\left(x_{n}, T(x)\right), d_{c}\left(x, T\left(x_{n}\right)\right)\right)
\end{aligned}
$$

Karena $\varphi$ merupakan fungsi kontinu, maka untuk $n \rightarrow \infty$ diperoleh 


$$
\begin{aligned}
d_{c}(x, T(x)) & \precsim 0+\frac{1}{2}\left[d_{c}(x, T(x))+0\right]-\varphi\left(d_{c}(x, T(x)), 0\right) \\
& =\frac{1}{2} d_{c}(x, T(x))-\varphi\left(d_{c}(x, T(x)), 0\right) \\
& \precsim \frac{1}{2} d_{c}(x, T(x))
\end{aligned}
$$

Hal ini berarti $d_{c}(x, T(x))=0$. Akibatnya, $T(x)=x$. Jadi $T$ mempunyai titik tetap.

Andaikan $x^{*}$ dan $x_{*}$ adalah titik tetap dari pemetaan $T$ dengan $x^{*} \neq x_{*}$. Perhatikan bahwa

$$
\begin{aligned}
d_{c}\left(x^{*}, x_{*}\right) & =d_{c}\left(T\left(x^{*}\right), T\left(x_{*}\right)\right) \\
& \precsim \frac{1}{2}\left[d_{c}\left(x^{*}, T\left(x_{*}\right)\right)+d_{c}\left(x_{*}, T\left(x^{*}\right)\right)\right]-\varphi\left(d_{c}\left(x^{*}, T\left(x_{*}\right)\right), d_{c}\left(x_{*}, T\left(x^{*}\right)\right)\right) \\
& =d_{c}\left(x^{*}, x_{*}\right)-\varphi\left(d_{c}\left(x^{*}, x_{*}\right), d_{c}\left(x^{*}, x_{*}\right)\right)
\end{aligned}
$$

Akibatnya, $\varphi\left(d_{c}\left(x^{*}, x_{*}\right), d_{c}\left(x^{*}, x_{*}\right)\right) \precsim 0$. Kontradiksi dengan $\varphi: \mathbb{C}^{+} \times \mathbb{C}^{+} \rightarrow \mathbb{C}^{+}$.

Oleh karena itu, $x^{*}=x_{*}$. Jadi $T$ mempunyai titik tetap yang tunggal.

\section{KESIMPULAN}

Ruang metrik kompleks merupakan perumuman dari ruang metrik dengan menggunakan metrik bernilai kompleks. Dalam artikel ini, ditunjukkan bahwa pemetaan C-kontraktif dan pemetaan C-kontraktif lemah memiliki titik tetap yang tunggal di ruang metrik kompleks.

\section{DAFTAR PUSTAKA}

Ahmad, J., Azam, A., \& Saejung, S., 2014. Common fixed point results for contractive mappings in complex valued metric spaces. Fixed Point Theory Appl., 67,:https://fixedpointtheoryandapplications.springer open.com/track/pdf/10.1186/1687-1812-2014-67.

Azam, A., Fisher, B., and Khan, M., 2011, Common fixed point theorems in complex valued metric spaces, Numer. Funct. Anal. Optim., vol. 32, no. 3, pp. 243-253.

Banach, S., 1922, Sur les operations dans les ensembles abstraits et leur application aux equations integrals, Fund. Math., vol. 3, pp. $133-181$.

Chatterjea, S. K., 1972, Fixed Point Theorems, C. R. Acad. Bulg. Sci., vol. 25, pp. 727-730, 1972.

Choudhury, S., 2009, Unique Fixed Point Theorem for Weakly C-contractive Mappings, Kathmandu Univ. J. Sci. Eng. Technol., vol. 5, no. I, pp. 6-13.

Rhoades, B. E., 2001, Some Theorems on Weakly Contractive Maps, Nonlinear Analysis: Theory, Methods and Applications, vol. 47, no. 4, pp.2683 - 2693. 